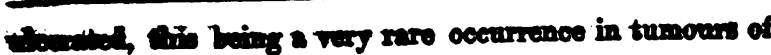
this dencription.

I. andien protrusion of the entive mass outside of the rive appears to have been owing to the bulk being diminished, in consequence of the circulation being stopped by the ligature; generally, this stoppage produces an enhrrement of the tumour, but, owing to the means of exit at the extremity of the tumour, I conceive that it was thus as it were emptied. The sudden shock and collapse that 80800 followed its removal, is a circumstance which I confess myself unable satisfactorily to explain; however, I think it not improbable that the withdrawal of so bulky a body from the surrounding viscers would be likely to give rise to a temporary faintness, but why it should prove fatal, I am at a loss to imagine. I am more inclined to attribute the fatal termination of the case to the previously exhausted condition of the patient, than to any step of the operation.

As to the relative value of the ligature and incision in the removal of such large tumours, the foregoing case has confirmed me in farour of the former, as I cannot but think that, had the tumour not been withdrawn so suddenly from the pelvis, we might have had a more favourable result. I say might have, because, as I have before stated, I am cf opinion that the modus operandi had nothing to do vith the unfortunate termination of the case.

Iiverpool, Octobar 1854

\section{ARSENIC A REMEDY FOR CHOLERA.}

\section{By C. BLACK, M.D., F.R.C.S., etc.}

THz following cases further attest the value of arsenic as a remedy for cholera.

CA8E 1. T. J., aged 28, groom, of strong and robust constitution, was attacked, on October 13th, at 10 P.y., with violent shivering, which was quickly followed by pains in the bowels attended by sickness and purging. These symptoms rapidly increased, and were shortly accompanied by cold skin, lividity of the lips and extremities, cadaverous expression of the countenance, cramps of the calves of the legs, a quick feeble pulse, and partial suppression of urine.

Oct. 13th. At 6 A.x., he had vomited and been purged twenty times. The eracuations were copious and watery ; at first slightly coloured; afterwards almost clear, and interspersed with numerous flakes, similar to minute masses of coagulated albumen. The vomit was at first somewhat yellow; afterwards, it was like clear water. I ordered three drops of liquor arsenicalis every half hour; also cold water to drink, and friction and artificial warmth to the lower extremities.

8 A.m. He had not romited since taking the first dose of liquor arsenicalis. He had been purged once. The cramps were less frequent and severe; the skin was becoming slightly warm; the pulse was somewhat stronger, 110 per minute.

10 A.x. There was neither sickness nor purging. Now and then, there were slight cramps in the calves; the skin was becoming warm; the pulse was 100, firmer; he had thirst.

4 P.M. He was improved in all respects. There was neither sickness, purging, nor cramps. The skin was hot and perspiring. The pulse was full, strong, 96 per minute; the tongue slightly furred; he had thirst; he had passed about two tablespoonfuls of urine.

Oct. 14th. He was convalescent.

Rema kKs. The symptoms, in this case, were urgent from the moment of attack; yet the vomiting was arrested by the first dose of arsenic, and but one evacuation from the bowels subsequently occurred. Close interrogation could elicit nothing as to the exciting cause of the attack. The patient had pursued his ordinary labour on the 12th; he had taken no supper the night before, and felt quite well on retiring to rest. The locality, however, in which he lived wo divts, badly drained, with on cpen cower in fow of his door; the house is mall, dart, badly rentilated, tro feet below the level of the street, and about thinty jands from the church-yand. The probable cause of attack, there fore, appears to be an atmospheric poison an opimion which will be further substantiated by the relation of the secceeding cases. Three drops of the liquor arsenicalis at once arrested the urgent symptoms; and forty-eight droper stored the patient to convalescence.

Case Ir. A. J., aged 23, a draper's assistant, of delieate constitution, was attacked, at 1 A.M. on Oct. 23rd, with violent shivering, followed quickly by vomiting and pury ing. At 3 A.M., he had romited twenty times and been purged twelve times. There were now great coldness of the skin, which was bedewed with a clammy moisture, collapsed features, blueness of the lips and nails, coldness of the breath, rox cholerica, almost incessant cramps of the extremities and abdomen, suppression of urine, and quick, flutiering, almost imperceptible pulse. The cramps were so violent, that the patient, while his voice remained, gave earnest expression to his sufferings. The dejections were copious (frequently three pints at one evacuation), almost clear, had a sickly odour, and contained flaky matter. The vomits were at first slightly coloured by bile; afterwnrds, they were clear and watery. I ordered four drops of liquor arsenicalis every half hour; cold water; and constant friotion with hot flannels to the whole body.

6 A.M. He had been purged six times, and had romited four times, since last visit. There was less cramp; there still were great coldness of the skin, and other symptoms of collapse; but he expressed himself as feeling better. The pulse was more distinct, 120 per minute. He spoke in a whisper, with tubular note; he had urgent thirst. The remedies were continued.

9 A.x. He had vomited three and been purged four times since the last visit. He felt better; the skin was becoming warm; he had slight twinging pains in the muscles of the abdomen and calres of the legs; the pulse was stronger, 110 per minute; he had thirst.

2 P.M. There had been neither purging nor vomiting since the last visit. Now and then, there was slight pain in one or the other calf; the countenance was becoming injected; the skin was warm; the pulse was full, 96 per minute; the tongue was red at the tip, and covered with a white fur over the remainder of its dorsum. He had not yet passed urine. The liquor arsenicalis was continued every two hours.

Oct. 24th, 10 A.M. He had passed a comfortable night. Sickness and purging were entirely absent. The skin was hot and perspiring; the pulse was 96 , full and strong; the tongue was covered with a slight white fur, except at the tip and along the centre of its dorsum, where it was red; he had considerable thirst. The voice was improved. He had passed scarcely an ounce of urine since the beginning of the attack. The following mixture was prescribed.

Po Liquoris ammonia acetatis $\frac{3 \mathrm{ij}}{\text {, }}$

Spiritús ætheris nitrosi $\mathbf{j} \mathrm{ij}$,

Vini antimonii potass.-tart. $3 \mathrm{ss}$,

Misture acacia $z_{j}$

Aquæ ad 弓riij.

Capiat cochlearia ampla dno secundis horis.

Oct. 25 th. IIc was better in all respects. The urinary secretion was re-established.

Oct. 26th. He was convalescent.

RFMARKs. This was the most severe and urgent case which I have ever witnessed in.this neighbourhood; and, had it occurred in the midst of acknowledged cases of malignant cholera, it would doubtless have been classed under that head. Its attack was sudden, rirulent, and, in a very few hours, had reduced the patient to the verge of the grave. It began without any appreciable exciting cause; the patient having, according to custom, partaken, the night before, of a milk supper, and haring retired to rest in good health. Here, again, however, the specific cause of attack seemed to exist in the particular locality in which the patient lired. The house was situated on a declivity, 
in s low, humid parition, with its back six feet below the level of the ground behind. The only water drunk by the pationt was deoply tainted with decayed vegetable matter, to which a long season of drought had, for some weeks, rofricted the fer inhabitants of the locality. Notwithstanding the violence of the symptoms, the exhibition of arsenic exerted an immediate and beneficial effect on the disease; and ninety-sir drops restored the patient to convalescence. Blight consecutive fever followed, which, however, quickly jielded to the remedies employed; and, in a week after the commencement of the attack, the patient returned to his usual employment.

C $\triangle 8 \mathrm{III}$ II. H. D., aged 40, of square build and strong constitution, by trade a shoemaker, was seized with romiting and purging at six o'clock, $\Delta . x$, on October 25th. These symptoms continued to increase till evening, when I saw him about five o'clock. There were then great coldness of skin, shrunken features, quick small feeble pulse, altered voice, and violent pains in the bowels; but no cramps of the extremities. He had been purged eighteen times, and had romited twelve times. During the intervals of romiting, there was frequent and violent retching. The dejections were copious, watery, frothy, and but slightly coloured. Their odour was so offensive as to render the patient's apartment almost intolerable. The urine was diminished in quantity, and passed at long intervals. I ordered three drops of liquor arsenicalis every half hour; also cold water to drink, and artificial warmth to the body.

7 P.x. He had not vomited, or been purged, since taking the first dose of medicine; and felt better.

10 P.M. He had no sickness or vomiting; the skin was becoming warm; the pulse was more distinct; he complained of thirst. He had not passed urine since midday.

October 26th. 9 A.M. He was purged once at $t$ welve o'clock on the previous night, and again at six this morning. The evacuations were said to be less offensive. He had no sickness during the night; the expression of the countenance was improved; the bowels were easy; the skin was warm and perspiring; the pulse was stronger, 96 per minute; he had passed about two ounces of urine during the night.

Henceforth, the case rapidly improved; and, on the 28th, convalescence was established; the patient having taken, in all, seventy-two drops of the arsenical solution.

REMarks. This case was rapidly passing into complete collapse at the time I first saw it. Nevertheless, the exhibition of arsenic was attended by immediately good results, namely, the instant arrest of romiting, and the diminution in the frequency of the alvine discharges. The peculiarly offensive and sickly nature of these discharges indicated very strongly the existence of a blood-poison, which was probably in this case also owing to the locality in which the patient lived. The house was small, dark, badly ventilated, two feet below the level of the adjoining street, the surface of which was extremely filthy, and the drainage, through which flowed the contents of drains from a higher part of the town, bad. The immediate and rapid improvement which followed the exhibition of arsenic, may fairly be ascribed to the influence of that remedy, since no other part of the treatment was calculated to effect so sudden a change; nor was the course of the disease at all tending towards an improvement.

CAsE IV. L. S., aged 32, of spare and delicate habit of body, by trade a blacksmith, was seized, at 2 A.M., on Oct. $27 \mathrm{th}$, with vomiting and purging. These symptoms continued to increase during the day, and at five o'clock P.M. I saw him. The countenance was pale, haggard, and shrunk; skin cold; breath cold; voice reduced to a whisper; pulse small, quick, and extremely feeble; violent cramps in the abdomen and calves of the legs; partial suppression of urine. Could not say how often he had romited and purged during the day ; but the dejections had been almost incessant. The discharges were copious, thin, frothy, almost colourless, and of extremely sickly and offensive odour. The vomits were copious, thin, and like slightly discoloured water. I ordered him to take three drops of liquor arse- nicalis overy half-hour; alvo to drint cold water, and have artificial warmth applied to the body.

7 P.X. He had been purged and had romited immediately after taking the first dose of the medicine. A second dose, given very shortly afterwards, was retained. The other symptoms remained the same.

10 P.x. The romiting and purging were abated; he had no cramps; the skin was becoming warmer; the pulse was 110 , more distinct, lut feeble; the tongue was fiery red along the centre of the dorsum, and covered with a slight white fur at the sides; he had considerable thirst.

Oct. 28th. 9 s.m. He was purged at two, five, and seren, A.x. The motions were less offensive; he had no sickness; the skin was warm and slightly perspiring; he had slight occasional nipping pains in the abdomen and legs; the expression of his countenance was more natural; the voice was much improved; the pulse was soft, regular, equal, 96 per minute. He had passed three ounces of urine during the night.

5 P.M. He had had neither sickness nor vomiting since last visit. In all respects he was considerably improved. He was ordered to take the liquor arsenicalis every two hours.

Henceforth the case progressed favourably; and, on the 30th instant, perfect convalescence was established.

REMARKs. The above case must be regarded as one of the worst attacks of English cholera, and yet a single dose of the arsenic was sufficient to permanently arrest the romiting; whilst a few more doses completely checked the purging. The discharges here, as in the previous case, were peculiarly offensive; whilst the condition of the patient, as to house, ventilation, and drainage, was likewise very similar. Thus, the house in which the patient lived is from one to two feet, at its ground-flcor, below the level of the adjoining alley; it is situated about ten yards from the church-yard, and small; the rooms are low, and the drainage and ventilation bad. Several open sewers exist within a short distance of the house, and from these noxious emanations constantly arise. These circumstances, and the peculiar odour of the alvine discharges, showed the probable dependence of the disease on the presence of a poison in the blood; whilst the result of the treatment demonstrates the efficiency of arsenic in destroying the power of such poison.

Chesterfield, Sor. 4th, 1851.

\section{CASE OF STRANGULATED HERNIA,}

IN WHICH THE INTESTINAL OBSTRUCTION CONTINOED FIVE DAYS AFTER OPERATION.

By GEORGE MALLETT, Esq.

Two caces of intestinal obstruction have recently been made public in this Jodrsat. In one, the propriety of using the knife for its relief was adrocated and employed; in the other, very powerful purgatives. I am of opinion that the old and often repeated quotation is true in such cases, and indeed in most others-" in medio tutissimus ibis"; of the truth of which remark the following case is, I think, an illustration.

Case. Oct. 13th. I was requested by Mr. Bancroft to visit a patient, upon whom he had been in attendance for a few days. Upon inquiry, I found the patient was a man about sixty-five years old; and that the bowels had not been moved for three or four days. There was also constant romiting. Aperient medicine had been given, and injections administered, without effect. The abdomen being examined, a large umbilical hernia was discovered, evidently omental, and probably irreducible, as it had not been returned for several years; but it had hitherto caused no inconvenience. Mr. Bapcroft had previously tried to reduce it by the taxis, but without effect. The tumour was tense, painful upon pressure, and the surrounding parts tender. The tongue was foul, but not dry; pulse 80 . I made slight pressure upon the hernia ; but, as the patient complained of much increased pain in consequence, the attempt at 